\section{Temporary Preservation of Carcasses of Small Laboratory Animals containing Radioactive Isotopes}

THE safe disposal of carcasses containing radioactive isotopes often presents a difficult problem. Even if a specially designed incinerator is available, it is still important that the amount of radioactive isotope in the material to be burned is kept as low as possible.

If animal carcasses containing short-lived isotopes (particularly iodine-131 and phosphorus-32) could be conveniently preserved for a sufficient time to reduce the radioactivity to relatively innocuous levels before incineration, the task of collecting and disposing of the radioactive ash would be avoided.

A procedure has been worked out for the preservation of whole carcasses or portions of tissue of animals not greater than $3 \mathrm{kgm}$. in weight by sealing them in polythene bags together with a mixture of fresh bleaching powder and 'Vermiculite' (a commercial expanded mica).

The following details are essential to the success of the process.

(1) It is desirable to slit the carcass ventrally along the mid-line, if this has not already been done, before placing it in the bag.

(2) If the carcass is soiled with tissue fluid or blood, it should be dusted with bleaching powder and allowed to cool before being placed in the bag. This avoids the development inside the bag of heat due to the rapid interaction of the bleaching powder and organic matter. The heating may also be avoided by applying 'Vermiculite' to the opened carcass. The finer grades of this material absorb about four times their weight of fluid, and thus the interaction with the bleaching powder is slowed down.

(3) The open end of the bag (which should be made of the heavier gauges, 250-500, of polythene) should have been previously folded back in a double cuff, fold outwards, to protect the surfaces to be sealed from dust or organic matter.

(4) The weights of bleaching powder and 'Vermiculite' should each be not less than one-fifth of the weight of the carcass. This represents, in practice, a volume of about $300 \mathrm{ml}$. and 1,500 ml., respectively, per kgm. weight of carcass.

(5) The animal's claws should be cut before the start of the radioactive experiment. The feet of the carcass should be bound with adhesive tape, lint or bandage before it is placed in the bag to avoid the risk of puncturing the bag; for the same reason it is unwise to sever the feet of the animal with bone forceps lest sharp splinters are left.

(6) The bag should be sealed with a suitable type of electrically heated 'soldering-gun' so that only a small amount of air is included; but care should be taken in expelling the air not to blow dust on the surfaces to be sealed.

(7) The 'cocooned' carcasses should be stored in open containers to allow for free circulation of air outside the bags, until the radioactive isotope has decayed sufficiently for incineration.

Experiments which have been in progress for sixteen months have demonstrated the practicability of the method. The cocooned carcasses have been stored during this time in open tins in a black. painted hut on the roof of the Department of Pathology. For a period of about eight weeks during the early part of the experiment the mean daily maximum shade temperature, as recorded in the nearby
Geography School, was over $70^{\circ} \mathrm{F}$, and the temperatures inside the hut were certainly greater than this. In spite of these unusually severe conditions there was never any obvious sign of putrefaction, although there was a persistent odour of 'bleaching powder' in the hut.

Tests have shown that the presence of the 'Vermiculite' does not seriously impede the progress of the combustion in a gas-fired incinerator.

J. C. Boursnelt

Department of Biochemistry, and

Agricultural Research Council

Unit of Animal Reproductiva

Physiology and Biochemistry,

Department of Pathology,

M. H. GleEson-White

University of Cambridge. Oct. 5.

\section{'Erythrocytin' and 'Erythrochelatin'}

Is a recent communication', Beckett and Smith have described a thermolabile inhibitor acting on 8-hydroxyquinoline ('Oxine'), which is either liberated or produced by erythrocytes and for which they have proposed the term 'erythrocytin'. To avoid confusion, my associates and $I$ wish to direct attention to the fact that we have applied the same name to the clotting factor which we discovered in the erythrocytes $^{2}$. This agent resembles the clotting principle occurring in the platelets, but is considerably more potent and has properties sufficiently characteristic to warrant regarding it as a distinct substance. We considered the name 'erythrocytin' particularly suitable because the ending 'in' is the same as in thromboplastin. The term has been employed in several of our publications ${ }^{3-5}$ during the past year and in the titles of two of these communications $s^{8,4}$.

ARMAND $\dot{J}$. QUIOK

Department of Biochemistry,

Marquette University School of Medicine, Milwaukee 3, Wisconsin.

${ }^{1}$ Beckett, A. H., and Smith, W. G., Nature, 178, 742 (1956)

${ }^{2}$ Georgatsos, J. G., Hnssey, C. V., and Quick, A. J., A mer. J. Physiol., 181, 30 (1955); Quick, A. J., Georgatsos, J. G., and Hussey, C. V., Amer. J. Med. Sci., 228, 207 (1954).

${ }^{3}$ Hussey, C. V., and Kaser, M., Fed. Proc., 15, 279 (1956).

‘Quick, A. J., and Hussey, C. V., J. Lab. and Clin. Mfed., 46, 940 (1955).

${ }^{5}$ Quick, A. J., and Hussey, C. V., Amer. Med. Assoc. Arch. Int. Med., 97, 524 (1956).

We were unaware of the application by Dr. A. J. Quick and his associates during the past year of the hitherto unused term 'erythrocytin' to describe a clotting factor they discovered in erythrocytes. To avoid confusion attendant upon using the same term for two separate factors, we therefore propose renaming the factor we obtained from erythrocytes which inhibits the antibacterial activity of 8-hydroxyquinoline-a chelating agent. In future, we will therefore use the term 'erythrochelatin' instead of 'erythrocytin' to describe this inhibitor'.

\section{Chelsea Polytechnic, London, S.W.3.}

Pharmacological Laboratories,

A. H. BeckerT

Bradford Technical College, Bradford.

'Beckett, A. H., and Smith, W. G., Nature, 178, 742 (1956). 